\title{
Preparation of Poly(L,L-Lactide) Microparticles via Pickering Emulsions Using Chitin Nanocrystals
}

\author{
T. S. Demina ${ }^{10},{ }^{1,2}$ Yu. S. Sotnikova, ${ }^{1,3}$ A. V. Istomin, ${ }^{1}$ Ch. Grandfils, ${ }^{4}$ \\ T. A. Akopova $\mathbb{D}^{1}{ }^{1}$ and A. N. Zelenetskii ${ }^{1}$ \\ ${ }^{1}$ Enikolopov Institute of Synthetic Polymer Materials, Russian Academy of Sciences, 70 Profsoyuznaya St., 117393 Moscow, Russia \\ ${ }^{2}$ Institute for Regenerative Medicine, Sechenov University, 8-2 Trubetskaya St., Moscow 119991, Russia \\ ${ }^{3}$ Moscow Aviation Institute (National Research University), 4 Volokolamskoe Shosse, 125993 Moscow, Russia \\ ${ }^{4}$ Interfaculty Research Centre on Biomaterials (CEIB), Chemistry Institute, University of Liège, B6C Allée du 6 Aồt 11, \\ B-4000 Liege (Sart-Tilman), Belgium
}

Correspondence should be addressed to T. S. Demina; detans@gmail.com

Received 30 November 2017; Accepted 13 March 2018; Published 8 April 2018

Academic Editor: Renal Backov

Copyright ( 2018 T. S. Demina et al. This is an open access article distributed under the Creative Commons Attribution License, which permits unrestricted use, distribution, and reproduction in any medium, provided the original work is properly cited.

\begin{abstract}
The aim of the present study was to investigate an ability of chitin nanocrystals to be used as stabilizing components for fabrication of poly(L,L-lactide) microparticles via the Pickering oil/water emulsion solvent evaporation technique. The anisometric chitin nanocrystals were extracted from two different samples of crab shell chitin via acetic hydrolysis and analyzed using atomic force microscopy, dynamic light scattering, and FTIR spectroscopy. The extracted nanocrystals showed no difference in the chemical structure but possessed different morphology and aspect ratios as a function of raw chitin used. The effect of chitin nanocrystals characteristics and concentration in the aqueous phase on the total yield, size distribution, and shape and surface morphology of the prepared polylactide microparticles was evaluated.
\end{abstract}

\section{Introduction}

Polylactide micro- and nanoparticles are widely used as drug delivery systems and cell microcarriers $[1,2]$. To control the cell attachment, biocompatibility, and drug kinetic release, the particles could be coated with functional polysaccharides during or after a preparation procedure [3-6]. As an alternative, the surface of the particles could be modified using especially synthesized amphiphilic copolymers as functional macromolecular emulsifiers [7]. Another approach to fabrication of core-shell microparticles is based on the application of solid nanoparticles as stabilizing components, that is, preparation via the Pickering emulsions.

The Pickering emulsions, that is, emulsions stabilized by solid nanoparticles instead of molecular emulsifiers, provide a number of benefits, such as high resistance to coalescence and low amount of nanoparticles needed to stabilize an interface [8-10]. The Pickering emulsions were successfully used for preparation of a so-called magnetic polymer microspheres consisted of polystyrene core and $\mathrm{Fe}_{3} \mathrm{O}_{4}$ nanoparticle shells [11]. A range of polymeric nanoparticles made of polymer brushes or polymer-grafted particles of various natures could be also used for the Pickering emulsions, which allows one to synthetize new nanocomposites dedicated to specific applications [12-18]. Usage of biocompatible nanoparticles, such as hydroxyapatite, $\mathrm{SiO}_{2}$, proteins, lignin, flavonoids, and various polysaccharides, for the Pickering emulsion stabilization is especially interesting for food or biomedical applications [19-22]. Polysaccharides could be transformed into nanodimensional forms using controlled aggregation of macromolecules $[23,24]$ or extraction of nanocrystals via hydrolysis of amorphous regions of raw polysaccharides [25-27]. Nanocrystals extracted from cellulose, chitin, and starch are highly crystalline rigid nanoparticles, which morphology and size could significantly vary as a function of raw polysaccharide used [26]. The most widely used cellulose and chitin nanocrystals have a rod-like anisometric 

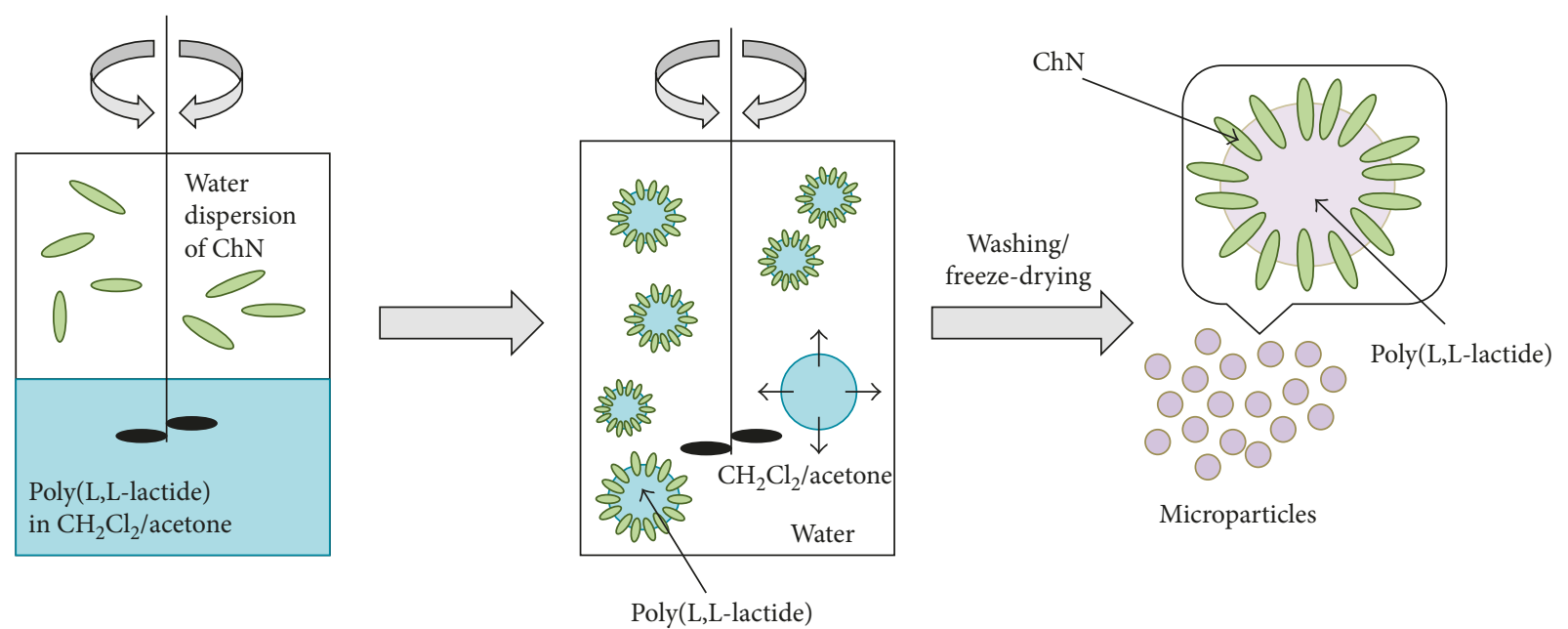

Figure 1: Scheme of PLLA-ChN core-shell microparticles preparation via Pickering oil/water emulsion solvent evaporation technique.

morphology with a length and diameter varied from several nanometers to micrometers. They are proposed as reinforcing fillers, templates for preparation of mesoporous materials, for fabrication of semiconductor and smart materials, including mechanically adaptive and self-healing ones. The use of polysaccharide nanocrystals as stabilizing agents in the Pickering emulsions was previously described mainly for food industry [28-31]. Efficiency of nanocrystals as stabilizing components for preparation of polymeric microparticles via the emulsion solvent evaporation technique was studied mostly on cellulose nanocrystals [32, 33].

This work was aimed at evaluating the effect of chitin source on characteristics of the obtained chitin nanocrystals and on a possibility to use them as stabilizing agents for fabrication of core-shell poly(L,L-lactide)/chitin microparticles via the Pickering emulsion solvent evaporation technique.

\section{Experimental}

2.1. Materials. Crab shell chitins were purchased from "Kombio" (Russia) and "Xiamen Fine Chemical" (China) and were used as raw materials for preparation of chitin nanocrystals, which were subsequently marked as $\mathrm{ChN}-\mathrm{K}$ and $\mathrm{ChN}-\mathrm{X}$, respectively. The ash contents of raw chitins were 0.16 wt.\% and 1.76 wt.\% for "Kombio" and "Xiamen Fine Chemical," respectively. The nanocrystals were obtained by acidic hydrolysis of the chitin samples according to the procedure described in $[34,35]$. Poly(L,L-lactide) (PLLA) with an average molecular weight of $160 \mathrm{kDa}$ was purchased from Sigma-Aldrich and used as a core material for the microparticle fabrication. Polyvinyl alcohol (PVA) marked as Mowiol 10-98 (Germany) was used as received.

2.2. Atomic Force Microscopy (AFM). The size and morphology of the prepared $\mathrm{ChN}$ were evaluated using atomic force microscopy NtegraPrima (NT-MDT, Russia) in tapping mode. The samples for AFM analysis were prepared as follows: 0.1 wt.\% aqueous dispersions were dropped on a cover glass and dried in a dust-free chamber [35]. The AFM images were analyzed using Image Analysis 2.0 (NT-MDT, Russia) software.

2.3. Dynamic Light Scattering. The mean size and size distribution of $\mathrm{ChN}$ in aqueous dispersions at concentrations of $0.1,0.5$ and $1 \mathrm{wt} . \%$ were evaluated by dynamic light scattering (DLS) using a Zetatrac particle size analyzer (Microtrac, Inc., USA) with the aid of Microtrac application software program (V.10.5.3).

2.4. FTIR. The chitin nanocrystals in a form of films cast from 1 wt.\% ChN aqueous dispersions were characterized by FTIR using a PerkinElmer Spectrum 100 FTIR spectrometer (PerkinElmer Inc., Wellesley, MA) equipped with universal ATR accessory with 8 scans at $4 \mathrm{~cm}^{-1}$ resolution.

2.5. Preparation of Poly(L,L-Lactide) Microparticles Stabilized with Chitin Nanocrystals. PLLA-ChN core-shell microparticles were prepared via Pickering emulsion solvent evaporation technique by mixing of $6 \mathrm{wt}$.\% solutions of PLLA in $\mathrm{CH}_{2} \mathrm{Cl}_{2}$ :acetone $(9: 1 \mathrm{v} / \mathrm{v})$ with $0.1-1$ wt.\% aqueous dispersions of $\mathrm{ChN}$. The scheme of the microparticle fabrication is shown in Figure 1. Briefly, the oil phase, that is PLLA solution, was rapidly added to $\mathrm{ChN}$ dispersion to achieve oil/water phase ratio as $1 / 9 \mathrm{v} / \mathrm{v}$. Microparticles stabilized with polyvinyl alcohol (PVA) solution (2.5 wt.\%) as emulsifier in aqueous phase were prepared as model samples. The mixing of the phases was carried out using a fourblade stirrer at a rotation speed of $700 \mathrm{rpm}$ for 3 hours. The emulsions were kept in a water bath through the mixing at $15^{\circ} \mathrm{C}$ during the first $15 \mathrm{~min}$, and, afterwards, the temperature was increased up to $30^{\circ} \mathrm{C}$. After the evaporation of the organic solvents, the obtained PLLA-ChN core-shell microparticles were collected, washed several times with deionized water and fractionated using sieves with apertures of $400,315,200$, and $100 \mu \mathrm{m}$, then, freeze-dried and weighted. 


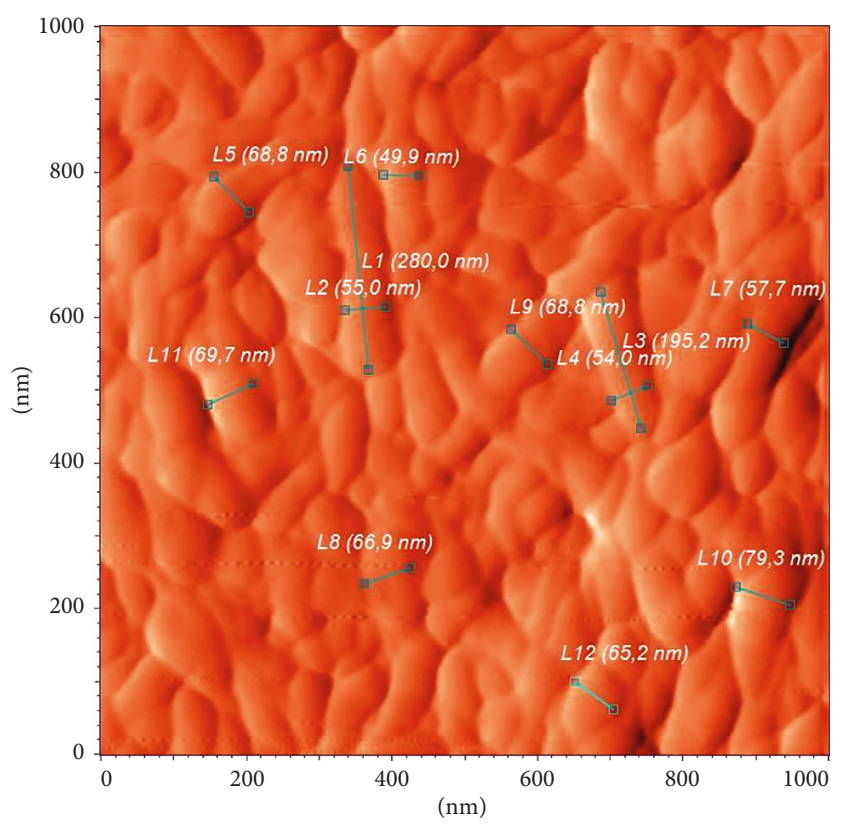

(a)

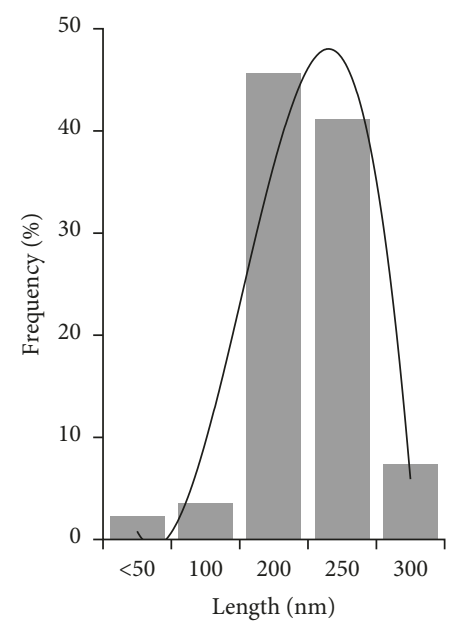

(c)

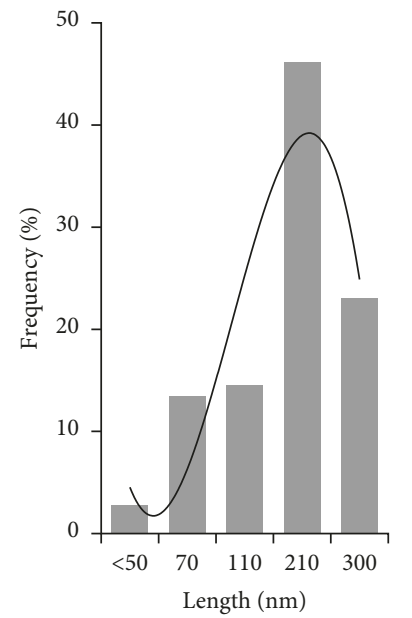

(e)

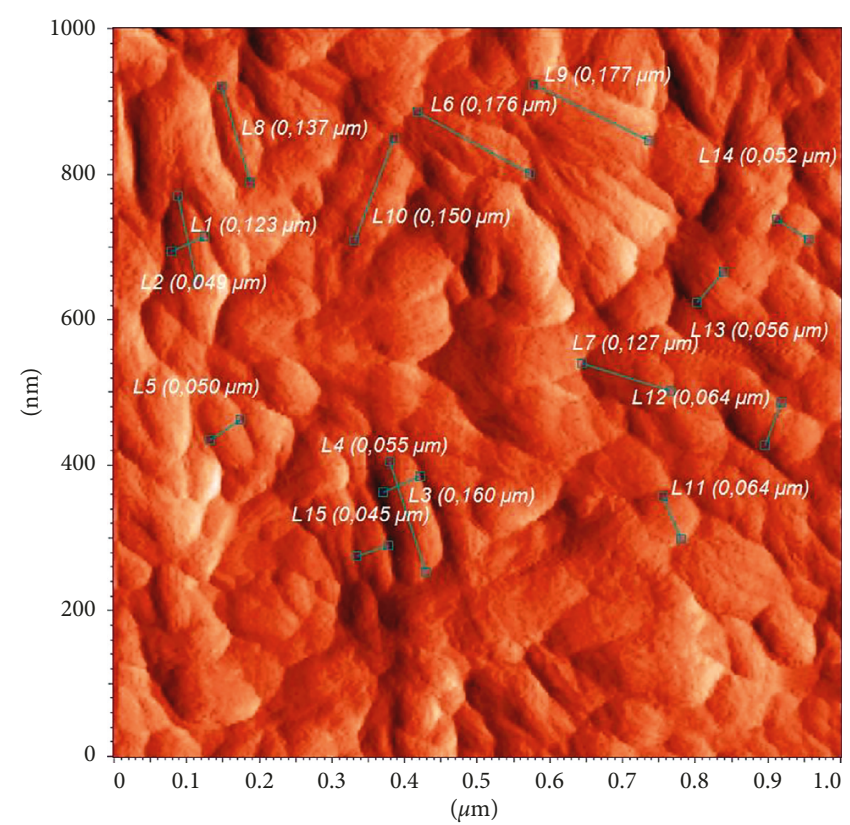

(b)

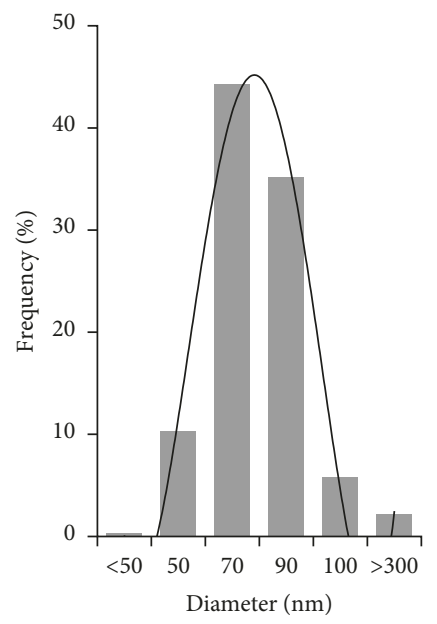

(d)

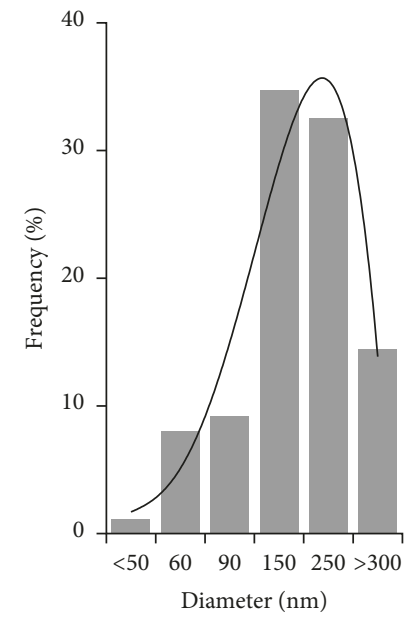

(f)

Figure 2: AFM images (a, b) and histograms of length (c, e) and diameter (d, f) distributions of ChN-X (a, c, and d) and ChN-K (b, e, and f). 


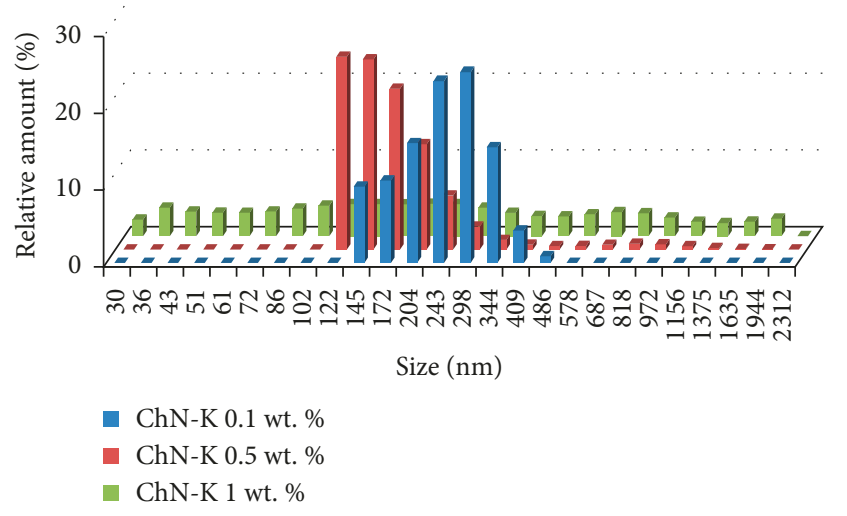

(a)

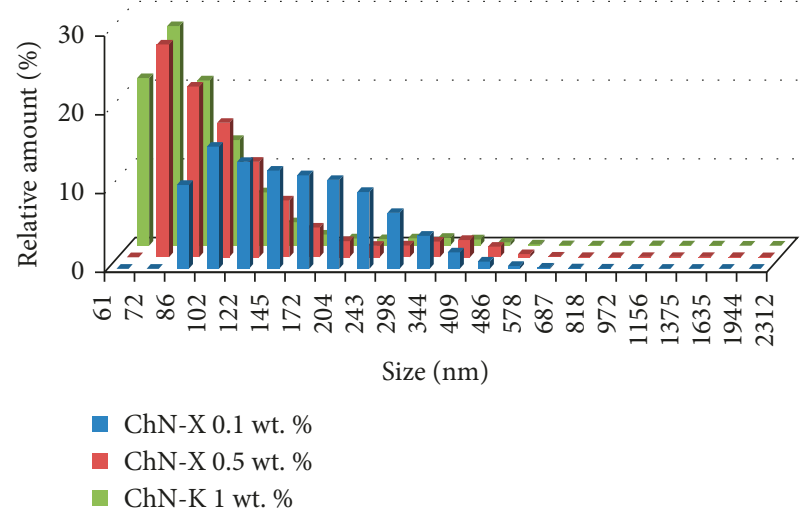

(b)

FIgURE 3: Number-weighted size distribution of $\mathrm{ChN}-\mathrm{K}$ (a) and $\mathrm{ChN}-\mathrm{X}$ (b) in their aqueous dispersions at various concentrations.

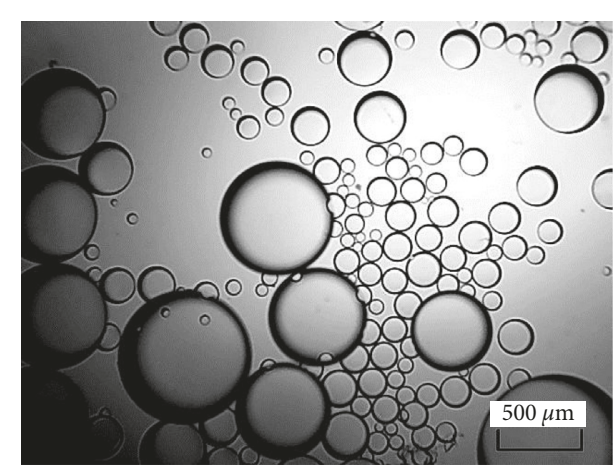

(a)

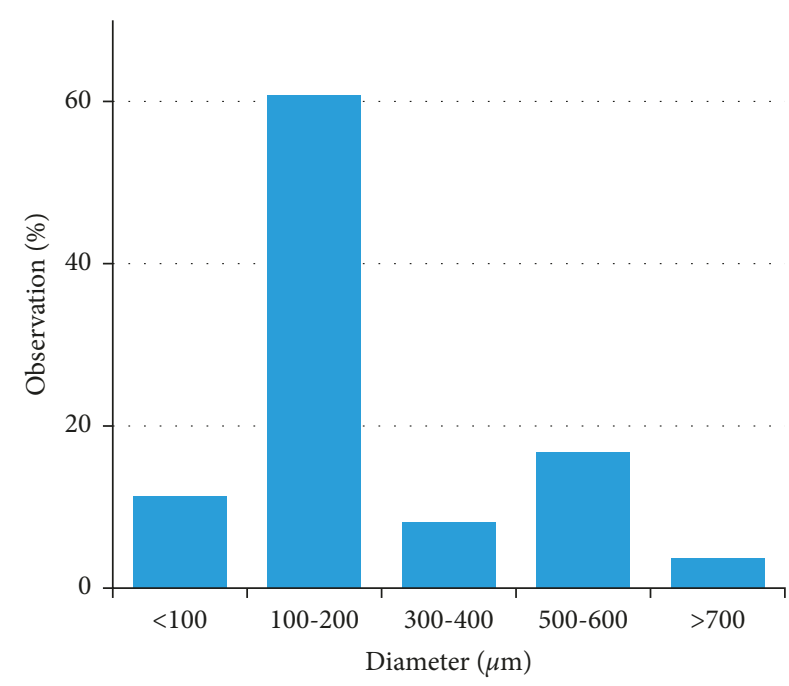

(b)

FIgUre 4: Optical micrographs of $\mathrm{CH}_{2} \mathrm{Cl}_{2} / \mathrm{ChN}-\mathrm{K}$ (1 wt.\%) emulsion (a) and oil droplet size distribution histogram (b).

2.6. Scanning Electron Microscopy. The surface morphology of the fabricated microparticles was studied by scanning electron microscopy (SEM) using PhenomProX (PhenomWorld, Netherlands) at $10-15 \mathrm{kV}$.

\section{Results and Discussions}

3.1. Chitin Nanocrystals Characterization. According to AFM, both types of the chitin nanocrystals had anisometric morphology that was strongly dependent on the chitin source (Figure 2). As could be seen from the calculation of the length and diameter of the nanocrystals, both types of samples had a rather wide size distribution, which was more pronounced for $\mathrm{ChN}-\mathrm{K}$ nanocrystals. The mean lengths of the nanocrystals were $181 \pm 63 \mathrm{~nm}$ and $131 \pm 94 \mathrm{~nm}$; diameters of $65 \pm 14 \mathrm{~nm}$ and $93 \pm 42 \mathrm{~nm}$ for ChN-X and $\mathrm{ChN}-\mathrm{K}$, respectively. The calculation of the nanocrystals dimensions showed that the $\mathrm{ChN}-\mathrm{X}$ had more anisometric morphology than $\mathrm{ChN}-\mathrm{K}$ : aspect ratios were of 2.8 and 1.4, respectively. Thus, in spite of both raw chitins were from crab shells, the structure of the polysaccharide could significantly vary as a function of animal source (species, parts, etc.) as well as conditions and quality of demineralization and deproteinization stages [36]. An X-ray analysis showed that a crystallinity of the extracted nanocrystals was higher than that of corresponding raw polysaccharides, while the positions of characteristic peaks were unchanged [35].

FTIR spectra of the extracted ChN showed no significant differences between the samples and contained a full set of typical characteristic bands of chitin, such as C-O stretching vibrations of pyranose cycle at $1070 \mathrm{~cm}^{-1}$, asymmetric bridge oxygen stretching at $1155 \mathrm{~cm}^{-1}$, the vibration of a $\mathrm{C}=\mathrm{O}$ group bonded to hydroxyl at $1619 \mathrm{~cm}^{-1}, \mathrm{CH}$ bending and symmetric $\mathrm{CH}_{3}$ deformations at $1376 \mathrm{~cm}^{-1}$ as well as a set of amide bands: Amide I at $1654 \mathrm{~cm}^{-1}$, Amide II at $1553 \mathrm{~cm}^{-1}$ and Amide III at $1309 \mathrm{~cm}^{-1}$ [37].

Since the fabricated $\mathrm{ChN}$ were intended to be used as stabilizing components for oil/water Pickering emulsions, their water dispersions were analyzed by DLS. As could be seen in Figure 3 the $\mathrm{ChN}-\mathrm{X}$ dispersions were less sensitive to 


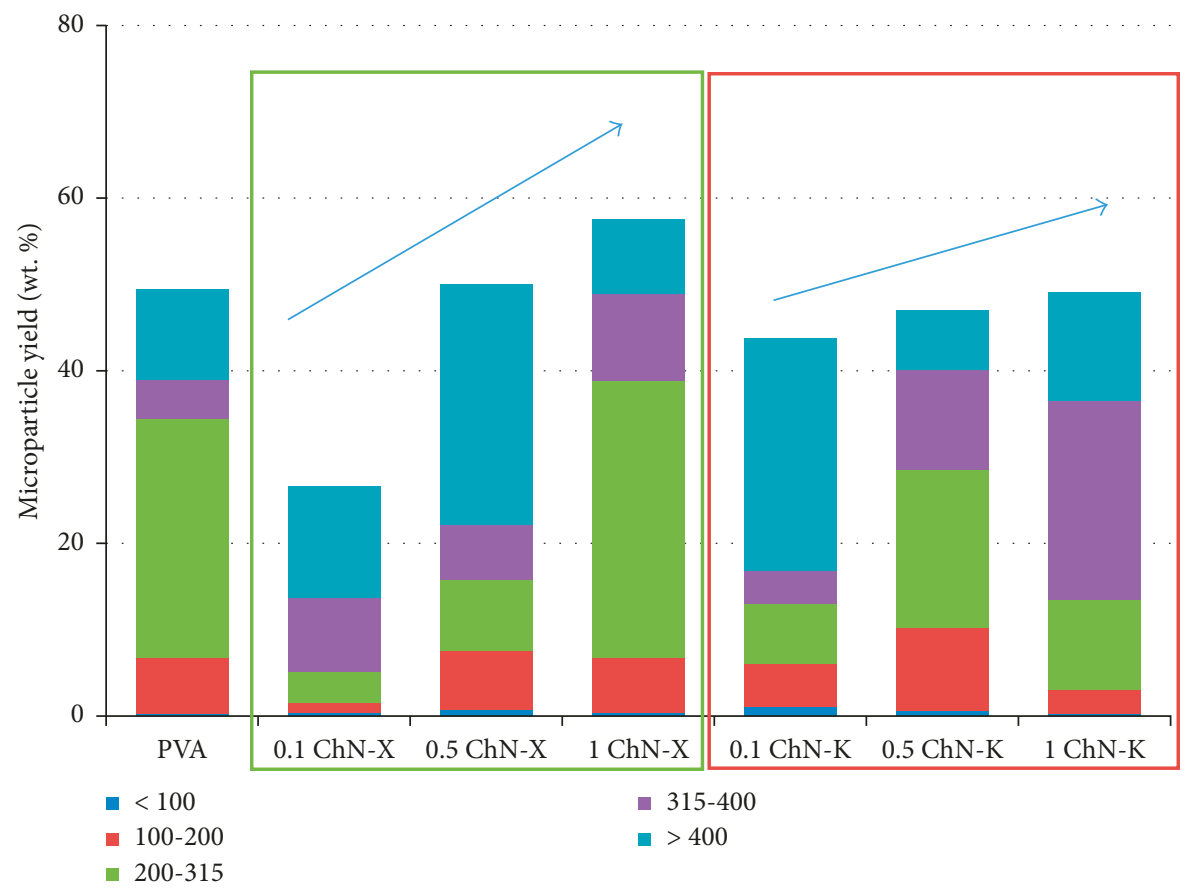

Figure 5: The total yield and microparticle size distribution as a function of origin and concentration of chitin nanocrystals in the aqueous phase.

the concentration change, while $\mathrm{ChN}-\mathrm{K}$ showed a widerange size distribution at $1 \mathrm{wt} . \%$ concentration.

Thus, the extraction of $\mathrm{ChN}$ allowed to prepare nanodimensional forms of chitins having chemical structure of native polysaccharides and anisometric morphology, which was varied in a range of 1.4-2.8 as a function of chitin source.

3.2. Microparticle Fabrication. As could be seen in Figure 4, the $\mathrm{ChN}$ could effectively stabilize a simple $\mathrm{CH}_{2} \mathrm{Cl}_{2}$ /water $(1 / 9 \mathrm{v} / \mathrm{v})$ emulsion. The size distribution of oil droplets depends on mixing parameters and effectiveness of oil/water interface stabilization, which is controlled by the $\mathrm{ChN}$ hydrophilichydrophobic balance and concentration in the aqueous phase.

Total yield, size distribution, and shape and surface morphology of the fabricated PLLA microparticles are additionally regulated by an arrangement of nanocrystals at the interface during the evaporation of the organic solvent and decreasing of the oil/water surface area. As could be seen in Figure 5, the total yield of the PLLA microparticles stabilized with $\mathrm{ChN}$ increased with increase in nanocrystals concentration in the aqueous phase and reached up to $58 \mathrm{wt} . \%$ in the case of $1 \mathrm{wt} . \%$ of $\mathrm{ChN}-\mathrm{X}$. This yield was higher than that obtained using PVA as the emulsifier in spite of lower amount of $\mathrm{ChN}$ in comparison with PVA concentration used: 1 and 2.5 wt.\%, respectively.

The comparative stabilization effectiveness of $0.1 \mathrm{wt} . \%$ $\mathrm{ChN}-\mathrm{K}$ was higher than that of $0.1 \mathrm{wt} . \% \mathrm{ChN}-\mathrm{X}$, but the impact of nanocrystals concentration in the aqueous phase was more pronounced for $\mathrm{ChN}-\mathrm{X}$ as compared with microparticles stabilized by $\mathrm{ChN}-\mathrm{K}$. Increase of the $\mathrm{ChN}-\mathrm{X}$ content in the aqueous phase led to a clear increase in stabilization effectiveness, that is, increase of total yield and decrease of mean microparticle size, while this dependence was not so obvious in the case of ChN-K. This difference could be caused by the narrower size distribution of $\mathrm{ChN}-\mathrm{K}$ nanocrystals and their better stability in the aqueous phase at the concentrations used (Figure 3).

SEM observations of all ChN-stabilized microparticles showed that they had more rough surface morphology than that of the ones stabilized using PVA (Figure 6). However, the shape of the fabricated PLLA-ChN microparticles was strongly varied as a function of origin and concentration of $\mathrm{ChN}$. The microparticles stabilized with $\mathrm{ChN}-\mathrm{X}$ and the ones stabilized with $\mathrm{ChN}-\mathrm{K}$ at the lowest concentration (0.1 wt.\%) had the spherical form, while the microparticles obtained using $\mathrm{ChN}-\mathrm{K}$ at higher concentrations (0.5 and $1 \mathrm{wt} . \%)$ had an irregular shape.

It could be assumed that the $\mathrm{ChN}$ particles were attached so firmly at the oil/water interface that their rearrangement during the solvent evaporation process was impaired. The excess of $\mathrm{ChN}$ entrapped at the interface was not so critical in the case of usage of low nanocrystals concentration (0.1 wt. $\%$ ), and the microparticles were able to remain in the spherical form (Figures 6(b) and 6(c)), while a presence of significant excess of $\mathrm{ChN}$ at the higher concentration in the aqueous phase could lead to the development of "raisin" effect. The difference in the shape of $\mathrm{ChN}-\mathrm{K}$ - and $\mathrm{ChN}$-X-stabilized microparticles could be caused by different aspect ratios of the nanocrystals: 1.4 and 2.8, respectively. The ChN-X entrapped at the interface could turn its orientation to the interface from lengthwise to crosswise, thus, to decrease the covered surface area. From another point of view, the higher stability of $\mathrm{ChN}-\mathrm{X}$ size at various concentrations (see DLS data) could be a reason of such behavior as well. 


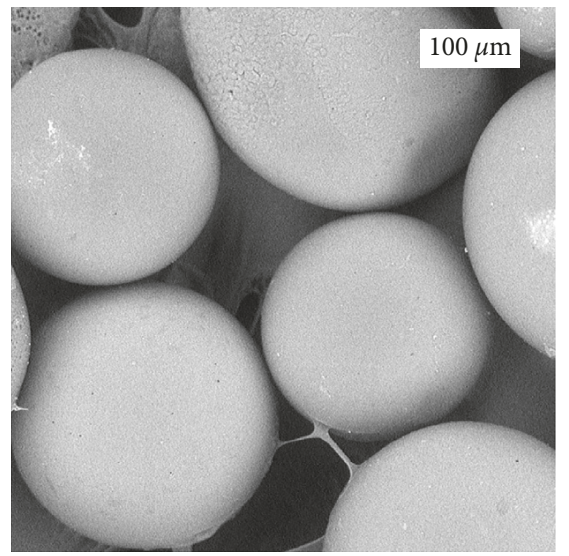

(a)

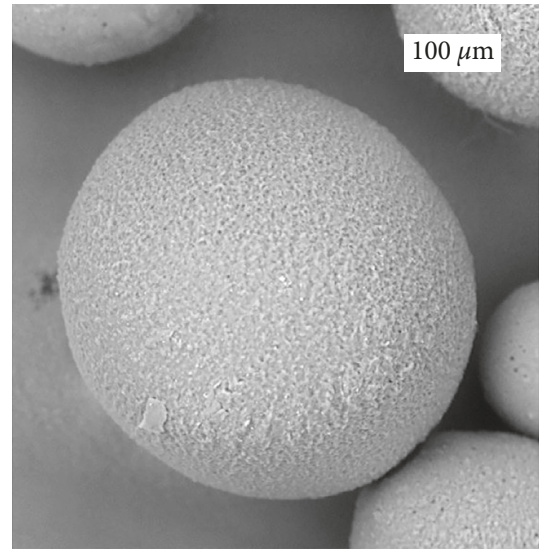

(b)

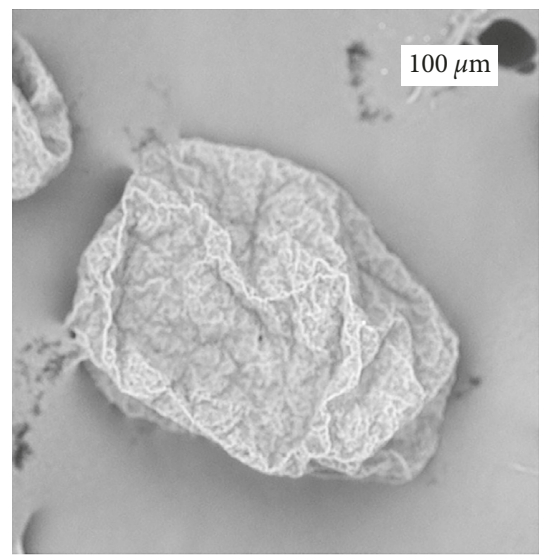

(d)

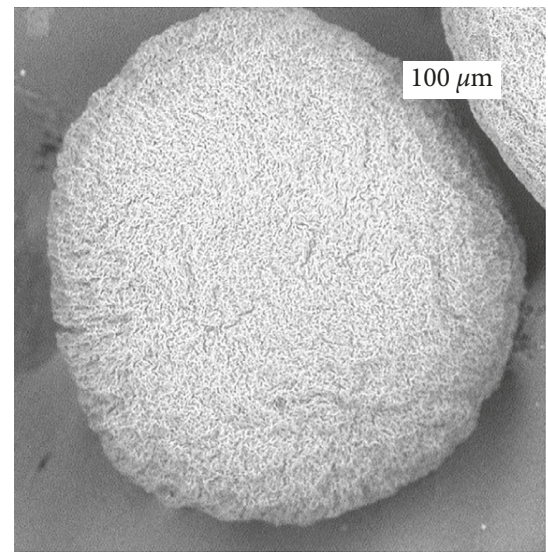

(c)

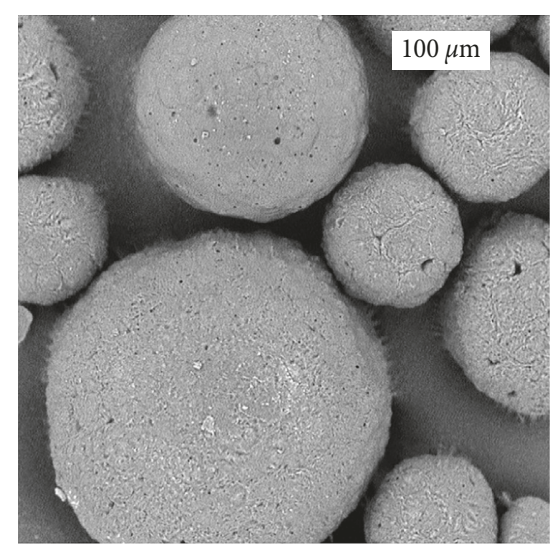

(e)

FIgure 6: Continued. 


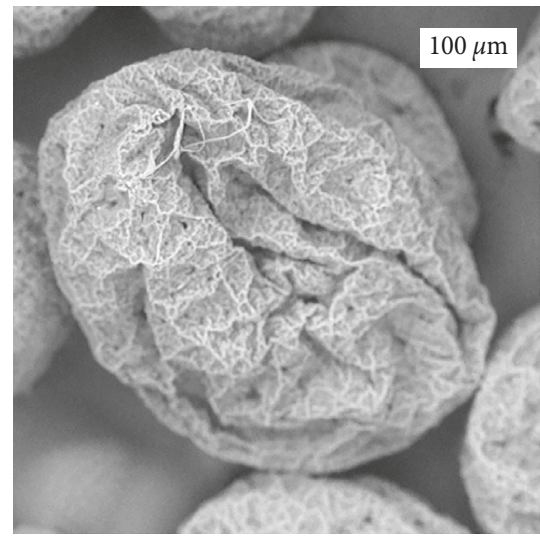

(f)

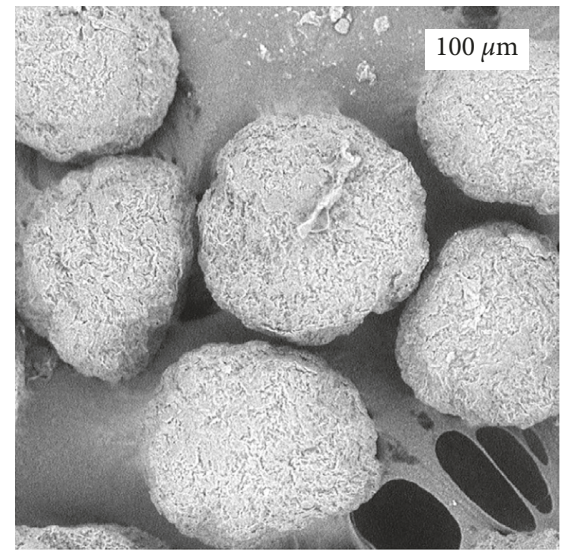

(g)

Figure 6: SEM images of the microparticles stabilized with PVA (a), ChN-K (b, d, f), and ChN-X (c, e, g) at concentrations of 0.1 (b, c), 0.5 $(\mathrm{d}, \mathrm{e})$, and $1 \mathrm{wt} . \%(\mathrm{f}, \mathrm{g})$ in the aqueous phase.

As a summary, chitin nanocrystals could effectively serve as a stabilizing component of oil/water emulsions during the preparation of polylactide-ChN core-shell microparticles, which total yield, size distribution, and shape were strongly depended on concentration, size, and size distribution of the nanocrystals used. These microparticles could be used as biodegradable cell microcarriers with improved cell affinity.

\section{Conclusions}

A promising approach to prepare poly(L,L-lactide) microparticles in a course of solvent evaporation from the Pickering oil/water emulsions stabilized with chitin nanocrystals has been discussed in terms of nanocrystals characteristics and processing parameters. Chitin nanocrystals extracted from two commercially available crab shell chitins showed different morphology and anisometric aspect ratios as well as an ability to be used as stabilizing agents in an aqueous phase during the preparation of polylactide microparticles via the solvent evaporation technique. The nanocrystals with higher aspect ratio allowed us to achieve a higher total yield of the fabricated spherical microparticles than that in a case of classical emulsifier application, that is, polyvinyl alcohol. The increase of nanocrystals concentration in an aqueous phase led to an increase in total yield and to decrease of mean microparticles size. The use of chitin nanocrystals with two fold lower aspect ratio at higher concentration in an aqueous phase caused the formation of microparticles with an irregular shape that could be explained by a lower ability of the nanocrystals to be rearranged at an interface during the solvent evaporation.

\section{Conflicts of Interest}

The authors declare that they have no conflicts of interest.

\section{Acknowledgments}

The authors are grateful to Dr. P. S. Timashev and his colleagues from the Institute of Photonic Technologies of
"Crystallography and Photonics" of the Russian Academy of Sciences and Institute for Regenerative Medicine of Sechenov University for the access to the equipment.

\section{References}

[1] B. Tyler, D. Gullotti, A. Mangraviti, T. Utsuki, and H. Brem, "Polylactic acid (PLA) controlled delivery carriers for biomedical applications," Advanced Drug Delivery Reviews, vol. 107, pp. 163-175, 2016.

[2] R. Dorati, A. DeTrizio, I. Genta et al., “An experimental design approach to the preparation of pegylated polylactide-coglicolide gentamicin loaded microparticles for local antibiotic delivery," Materials Science and Engineering: C, vol. 58, pp. 909-917, 2016.

[3] Y. Hong, C. Gao, Y. Xie, Y. Gong, and J. Shen, "Collagencoated polylactide microspheres as chondrocyte microcarriers," Biomaterials, vol. 26, no. 32, pp. 6305-6313, 2005.

[4] J. Wu, T. Kong, K. W. K. Yeung et al., "Fabrication and characterization of monodisperse PLGA-alginate core-shell microspheres with monodisperse size and homogeneous shells for controlled drug release," Acta Biomaterialia, vol. 9, no. 7, pp. 7410-7419, 2013.

[5] L. Lao, H. Tan, Y. Wang, and C. Gao, "Chitosan modified poly (L-lactide) microspheres as cell microcarriers for cartilage tissue engineering," Colloids and Surfaces B: Biointerfaces, vol. 66, no. 2, pp. 218-225, 2008.

[6] A. Privalova, E. Markvicheva, Ch. Sevrin et al., "Biodegradable polyester-based microcarriers with modified surface tailored for tissue engineering," Journal of Biomedical Materials Research Part A, vol. 103, no. 3, pp. 939-948, 2015.

[7] T. S. Demina, T. A. Akopova, L. V. Vladimirov, A. N. Zelenetskii, E. A. Markvicheva, and Ch. Grandfils, "Polylactide-based microspheres prepared using solid-state copolymerized chitosan and D,L-lactide," Materials Science and Engineering: C, vol. 59, pp. 333-338, 2016.

[8] Y. Chevalier and M.-A. Bolzinger, "Emulsions stabilized with solid nanoparticles: Pickering emulsions," Colloids and Surfaces A: Physicochemical and Engineering Aspects, vol. 439, pp. 23-34, 2013. 
[9] J. Wu and G.-H. Ma, "Recent studies of Pickering emulsions: particles make the difference," Small, vol. 12, no. 34, pp. 4633-4648, 2016.

[10] C. Linke and S. Drusch, "Pickering emulsions in foodsopportunities and limitations," Critical Reviews in Food Science and Nutrition, pp. 1-15, 2017, In press.

[11] C. Wang, C. Zhang, Y. Li, Y. Chen, and Z. Tong, "Facile fabrication of nanocomposite microspheres with polymer cores and magnetic shells by Pickering suspension polymerization," Reactive \& Functional Polymers, vol. 69, no. 10, pp. 750-754, 2009.

[12] J. O. Zoppe, R. A. Venditti, and O. J. Rojas, "Pickering emulsions stabilized by cellulose nanocrystals grafted with thermo-responsive polymer brushes," Journal of Colloid and Interface Science, vol. 369, no. 1, pp. 202-209, 2012.

[13] T. Saigal, H. Dong, K. Matyjaszewski, and R. D. Tilton, "Pickering emulsions stabilized by nanoparticles with thermally responsive grafted polymer brushes," Langmuir, vol. 26, no. 19, pp. 15200-15209, 2010.

[14] N. Popadyuk, A. Popadyuk, I. Tarnavchyk et al., "Synthesis of covalently cross-linked colloidosomes from peroxidized Pickering emulsions," Coatings, vol. 6, pp. 1-14, 2015.

[15] H. Guo, D. Yang, M. Yang, Y. Gao, Y. Liu, and H. Li, "Dual responsive Pickering emulsions stabilized by constructed core crosslinked polymer nanoparticles via reversible covalent bonds," Soft Matter, vol. 12, no. 48, pp. 9683-9691, 2016.

[16] K. S. Silmore, C. Gupta, and N. R. Washburn, "Tunable Pickering emulsions with polymer-grafted lignin nanoparticles," Journal of Colloid and Interface Science, vol. 466, pp. 91-100, 2016.

[17] J. Lu, W. Zhou, J. Chen, Y. Jin, K. B. Walters, and S. Ding, "Pickering emulsions stabilized by palygorskite particles grafted with $\mathrm{pH}$-responsive polymer brushes," RSC Advances, vol. 5, no. 13, pp. 9416-9424, 2015.

[18] Y. Zhu, J. Sun, C. Yi, W. Wei, and X. Liu, “One-step formation of multiple Pickering emulsions stabilized by self-assembled poly(dodecyl acrylate-co-acrylic acid) nanoparticles," Soft Matter, vol. 12, no. 36, pp. 7577-7584, 2016.

[19] Z. Wei, C. Wang, H. Liu, S. Zou, and Z. Tong, "Facile fabrication of biocompatible PLGA drug-carrying microspheres by O/W Pickering emulsions," Colloids and Surfaces B: Biointerfaces, vol. 91, pp. 97-105, 2012.

[20] F. Ye, M. Miao, B. Jiang et al., "Elucidation of stabilizing oilin-water Pickering emulsion with different modified maize starch-based nanoparticles," Food Chemistry, vol. 229, pp. 152-158, 2017.

[21] S. Ge, L. Xiong, M. Li et al., "Characterizations of Pickering emulsions stabilized by starch nanoparticles: influence of starch variety and particle size," Food Chemistry, vol. 234, pp. 339-347, 2017.

[22] T. Zeng, Z.-L. Wu, J.-Y. Zhu et al., "Development of antioxidant Pickering high internal phase emulsions (HIPEs) stabilized by protein/polysaccharide hybrid particles as potential alternative for PHOs," Food Chemistry, vol. 231, pp. 122-130, 2017.

[23] X.-Y. Wang and M.-C. Heuzey, "Chitosan-based conventional and Pickering emulsions with long-term stability," Langmuir, vol. 32, no. 4, pp. 929-936, 2016.

[24] W. W. Mwangi, K.-W. Ho, B.-T. Tey, and E.-S. Chan, "Effect of environmental factors on the physical stability of Pickeringemulsions stabilized by chitosan particles," Food Hydrocolloids, vol. 60, pp. 543-550, 2016.
[25] A. M. Salaberria, J. Labidi, and S. C. M. Fernandes, "Different routes to turn chitin into stunning nano-objects," European Polymer Journal, vol. 68, pp. 503-515, 2015.

[26] J. Huang, P. R. Chang, and N. Lin, Polysaccharide-Based Nanocrystals: Chemistry and Applications, Willey, Hoboken, NJ, USA, 2015.

[27] T. Abitbol, A. Rivkin, Y. Cao et al., "Nanocellulose, a tiny fiber with huge applications," Current in Opinion on Biotechnology, vol. 39, pp. 76-88, 2016.

[28] X. Zhai, D. Lin, D. Liu, and X. Yang, "Emulsions stabilized by nanofibers from bacterial cellulose: new potential food-grade Pickering emulsions," Food Research International, vol. 103, pp. 12-20, 2018.

[29] M. V. Tzoumaki, T. Moschakis, V. Kiosseoglou, and C. G. Biliaderis, "Oil-in-water emulsions stabilized by chitin nanocrystal particles," Food Hydrocolloids, vol. 25, no. 6, pp. 1521-1529, 2011.

[30] M. V. Tzoumaki, T. Moschakis, E. Scholten, and C. G. Biliaderis, "In vitro lipid digestion of chitin nanocrystal stabilized o/w emulsions," Food \& Function, vol. 4, no. 1, pp. 121-129, 2013.

[31] T. Angkuratipakorn, A. Sriprai, S. Trantrawong, W. Chaiyasit, and J. Singkhonrat, "Fabrication and characterization of rice bran oil-in-water Pickering emulsion stabilized by cellulose nanocrystals," Colloids and Surfaces A: Physicochemical and Engineering Aspects, vol. 522, pp. 310-319, 2017.

[32] I. Kalashnikova, H. Bizot, B. Cathala, and I. Capron, "New Pickering emulsions stabilized by bacterial cellulose nanocrystals," Langmuir, vol. 27, no. 12, pp. 7471-7479, 2011.

[33] N. Rescignano, E. Fortunati, I. Armentano et al., "Use of alginate, chitosan and cellulose nanocrystals as emulsion stabilizers in the synthesis of biodegradable polymeric nanoparticles," Journal of Colloid and Interface Science, vol. 445 , pp. 31-39, 2015.

[34] A. V. Istomin, T. S. Demina, E. N. Subcheva, T. A. Akopova, and A. N. Zelenetskii, "Nanocrystalline cellulose from flax stalks: preparation, structure, and use," Fibre Chemistry, vol. 48, no. 3, pp. 199-201, 2016.

[35] Yu. S. Sotnikova, T. S. Demina, A. V. Istomin et al., "Materials based on guar and hydroxypropylguar filled with nanocrystalline polysaccharides," Fibre Chemistry, vol. 49, no. 3, pp. 188-194, 2017.

[36] I. Younes and M. Rinaudo, "Chitin and chitosan preparation from marine sources. Structure, properties and applications," Marine Drugs, vol. 13, no. 3, pp. 1133-1174, 2015.

[37] M. L. Duarte, M. C. Ferreira, M. R. Marvao, and J. Rocha Duarte, "An optimised method to determine the degree of acetylation of chitin and chitosan by FTIR spectroscopy," International Journal of Biological Macromolecules, vol. 31, no. 1-3, pp. 1-8, 2002. 


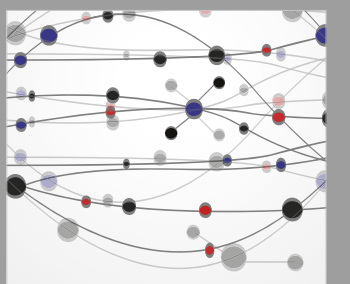

The Scientific World Journal
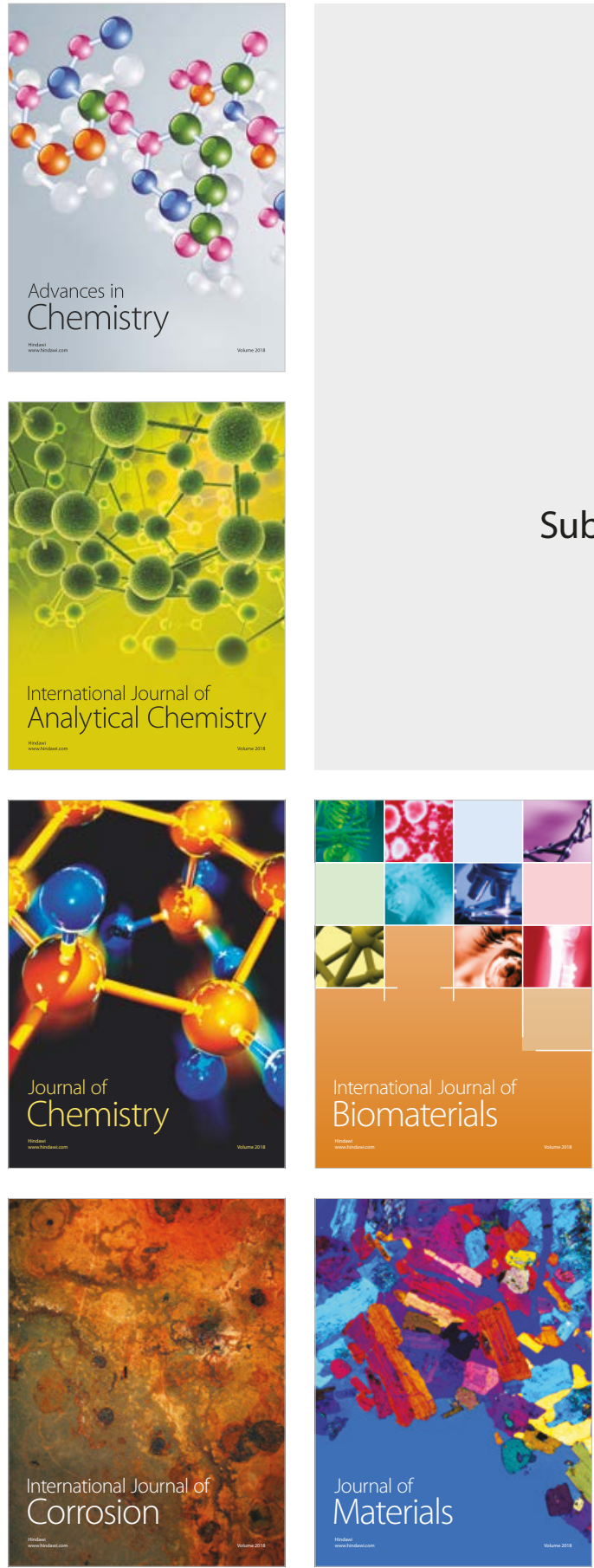

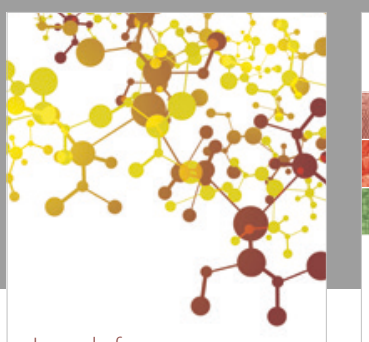

Journal of

Applied Chemistry
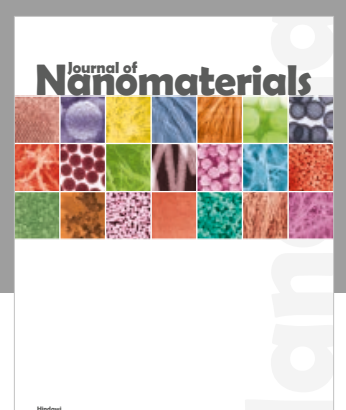

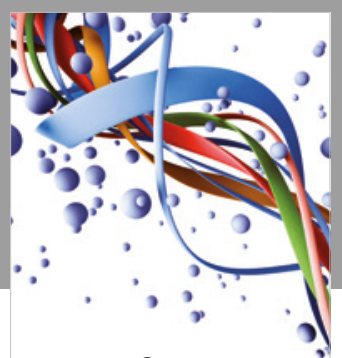

Scientifica

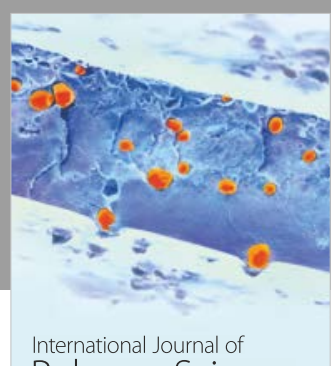

Polymer Science

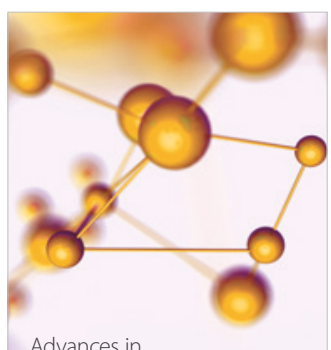

Physical Chemistry
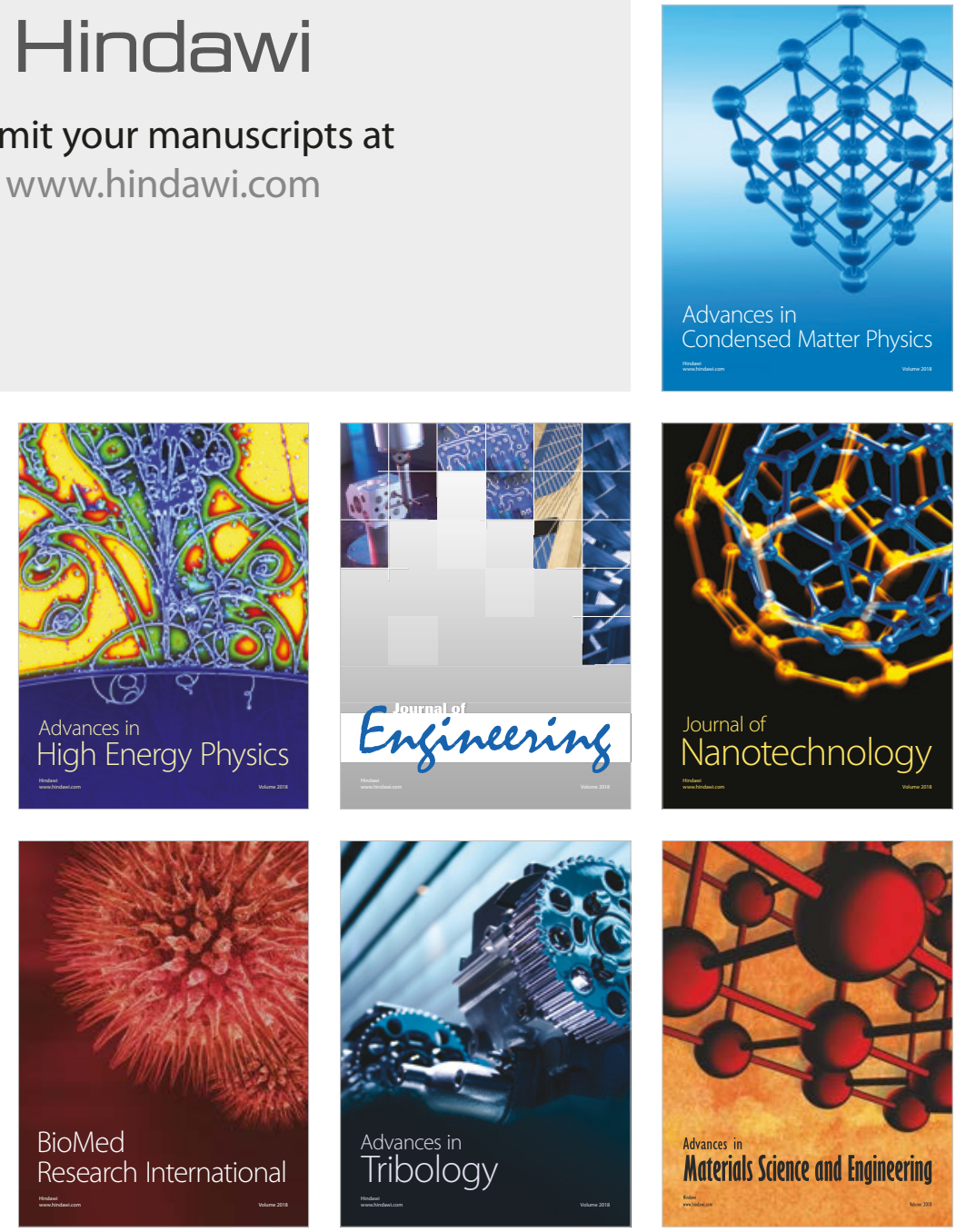